\title{
A new source of natural adhesive: Acacia mangium bark extracts co-polymerized with phenol-formaldehyde (PF) for bonding Mempisang (Annonaceae spp.) veneers
}

\begin{abstract}
Acacia mangium is a fast-growing dicotyledonous tree species and has become the dominating plantation in Malaysia. It was grown particularly as a raw material for veneer, pulp, and paper industries. The chemical properties test in this study showed that the A. mangium tree bark contains higher extractive content as compared to the wood portion (sapwood). Tannin extracts from A. mangium tree bark were found to be rich in phenolic compounds and had the potential to replace conventional phenolï formaldehyde (PF) adhesive used in the plywood manufacturing industry. Tannin adhesive (tanninï paraformaldehyde) prepared from A. mangium bark tannin by cross-linking with paraformaldehyde were used for bonding of Mempisang (Annonaceae spp.) plywood board. However, the resulting bonding strength using tannin adhesive was found to be only suitable for interior grade application. Further extension of its application for interior and exterior grade plywood could be achieved with addition of PF (co-polymerization with resol) during the production process. The optimized formulation of tannin adhesive consists of A. mangium solid extracts (90 parts), commercial PF (10 parts), and paraformaldehyde (3\%). Results have shown that the plywood shear strength complies with the requirement for European norms EN 314-1 and EN 314-2:1993, which includes the dry test, cold water test, and the boiling test.
\end{abstract}

Keyword: Adhesion by mechanical interlocking; Composite; Phenolic; Adhesive for wood 